\begin{tabular}{|c|c|}
\hline \multirow{3}{*}{ 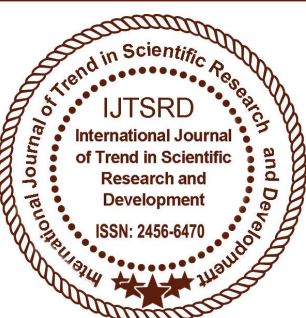 } & $\begin{array}{l}\text { International Journal of Trend in Scientific } \\
\text { Research and Development (IJTSRD) }\end{array}$ \\
\hline & Access Journal \\
\hline & ISSN No: 2456 - 6470 | www.ijtsrd.com | Volume - 2 | Issue -3 \\
\hline
\end{tabular}

\title{
Role of UPQC in Distributed Generation Power System: A Review
}

\author{
Sajid Bashir \\ M.Tech Scholar, Electrical Engineering Department \\ YIET, Gadhauli, Yamunanagar, Haryana
}

\author{
Gagan Deep Yadav \\ Assistant Professor, Electrical Engineering, \\ Department YIET, Gadhauli, Yamunanagar, Haryana
}

\section{ABSTRACT}

The ever increasing share of renewable energy sources (RERs) in the today's scenario, the power grids are suffering from poor power quality due to the intermittent nature of wind and solar based power generating units. The led to extensive research in the field of power quality especially in voltage and frequency regulations Distributed generation involving RERs has become more popular in recent years due to technological advancement and has been started increasingly used in industry. It has become more important to understand the integration of these systems through PE interface with the existing electric power systems networks. At the same time, high frequency switching of Power Electronic interface has caused major Power Quality concerns, which has been tackled with the help of Custom power devices interfaces that has allowed DG to offers various benefits like ability to provide ancillary services, increased energy efficiency, increased functionality through improved power quality and voltage/VAR support, improved electrical system reliability by reducing the fault contributions, and flexibility in operations with various other DE sources. DG also allows the customer to have a choice while it reduces the overall interconnection costs. This paper focuses on widespread use of DG through various Renewable Energy Sources, Power Quality issues associated with the use of Power Electronic interface and use of various Custom Power Devices to improve Power Quality. It particularly evaluates the role of UPQCDG in various modes of $\mathrm{DG}$ in following $\mathrm{PQ}$ standards.

Keywords: Ancillary services, Frequency response, Emulating inertia, Primary frequency control, Wind turbines

\section{INTRODUCTION}

Distributed generation has become more popular in recent years due to technological advancement and has been started increasingly used in industry. It has become more important to understand the integration of these systems through PE interface with the existing electric power systems networks. At the same time, high frequency switching of Power Electronic interface has caused major Power Quality concerns, which has been tackled with the help of Custom power devices interfaces that has allowed DG to offers various benefits like ability to provide ancillary services, increased energy efficiency, increased functionality through improved power quality and voltage/VAR support, improved electrical system reliability by reducing the fault contributions, and flexibility in operations with various other DE sources. DG also allows the customer to have a choice while it reduces the overall interconnection costs. This paper focuses on widespread use of DG through various Renewable Energy Sources, Power Quality issues associated with the use of Power Electronic interface and use of various Custom Power Devices to improve Power Quality. It particularly evaluates the role of UPQC-DG in various modes of DG in following PQ standards.

It may play vital role in the future energy generation systems and power system structure. In general, the definition of DG has been suggested as follows: Distributed generation is an electric power source connected directly to the distribution network or on the customer site of the meter. On the base of legal definition, distribution and transmission networks have been distinguished as, transmission networks is usually part of the electricity market regulation and anything that is not defined as transmission network 
in the legislation, can be regarded as distribution network. One of the major benefits of DG is the possibility of improving the continuity of power supply. This apart, there are significant benefits for the energy supplier such as released line capacity that makes a transmission/distribution line up-grade unnecessary, reduced transmission and distribution congestion, grid investment postponement and improved grid utilization and the ability of the DG system to provide ancillary services such as voltage stability, contingency reserves and VAR compensation which subsequently reduces overall cost by eliminating the need for voltage control equipment. DG uses only locally measurable variables feedback as controlling techniques that allows correct system operation and switching between parallel and isolated modes without needing online communication of control signals between the generators. Depending on economics there are a wide variety of applications for DE systems like backup and emergency power, base load power, and peaking power in addition to offering a combined heat and power (CHP) option if the customer has a use for the thermal heat generated by the DE system [1].

\section{Challenges and Scopes}

The integration of the DG with the utility distribution network offers a number of technical, environmental and economic benefits. It also gives a great opportunity for distribution utilities to improve the performance of networks by reducing its losses [2]. The technical challenges associated with the DG can be subdivided into three categories namely, system interface to the grid, operation and control of the DG and planning and design. Reactive power compensation is an important issue in the control of distribution systems. Reactive current increases the distribution system losses, reduces the system power factor, shrink the active power capability and can cause large-amplitude variations in the load-side voltage. Moreover, rapid changes in the reactive power consumption of large loads can cause voltage amplitude oscillations. This might lead to a change in the electric system real power demand resulting in power oscillations. The introduction of DG on the distribution systems can significantly impact the flow of power and voltage conditions at customers and utility equipment[3].Three major factors are now pushing forward the development of distributed resources for electric power generation are discussed in [4]. The first one is the possibility of making exploitable several kinds of sources such as renewable and co-generation sources (combined heat and power: CHP). The second factor is associated with the increased difficulties met in developing new transmission and distribution facilities and to the current high levels of power flows in some critical grid sections. The last factor regards the high levels of power quality needed by an increasing number of activities. Such levels cannot be ensured by the standard distribution systems.

\section{Power Electronics Interface}

PE interfaces offer unique capabilities over traditional interconnection technologies and can convert almost any form of electrical energy to a more desirable and usable form which is the reason why $\mathrm{PE}$ based systems is ideal for DE systems. With reducing cost of PE and associated control systems, these types of interconnection interfaces have become more prevalent in use with all types of DE systems. Another benefit of PE is their extremely fast response time to power quality events or fault conditions within in the sub-cycle range which enable advanced applications such as the operation of intentional islands (micro grids) for high-reliability applications and reducing fault level currents of distributed generation. The PE interface can also contain protective functions for both the distributed energy system and the local electric power system that allow paralleling and disconnection from the electric power system. The PE interface will also contain some level of metering and control functionality. This will ensure that the distributed energy system can be operated as designed.

\section{PQ Issues and Custom Power Devices}

The main purpose of the PE converters is to integrate the DG to the grid in compliance with power quality standards. However, high frequency switching of inverters can inject additional harmonics to the systems, creating major PQ problems if not implemented properly [5].Custom Power Devices like STATCOM (Shunt Active Power Filter), DVR (Series Active Power Filter) and UPQC (Combination of series and shunt Active Power Filter) are the latest development of interfacing devices between distribution supply (grid) and consumer appliances to overcome voltage/current disturbances and improve the power quality by compensating the reactive and harmonic power generated or absorbed by the load [6].UPQC is the integration of series and shunt active 
filters, connected back to back on the dc side and share a common DC capacitor. The series component of the UPQC is responsible for mitigation of the supply side disturbances, voltage sags/swells, flicker, voltage unbalance and harmonics. It acts as series connected compensating voltage source so as to maintain the load voltages at a desired level; balanced and distortion free. The shunt component is responsible for mitigating the current quality problems such as poor power factor, load harmonic currents, load unbalance etc. caused by the consumer. It injects currents in the ac system such that the source currents become balanced sinusoids and in phase with the source voltages [7].

\section{Various Modes of Operation of DG}

As UPQC has no capability in compensating the voltage interruption because there is no energy storage, a novel scheme has been suggested to integrate UPQC in DG systems in [8]. It explored two configurations namely DC Linked system and Separated DG-UPQC system. In DG - UPQC DClinked configuration shown in Fig.1 (a), DG sources are connected to a DC link in the UPQC as an energy source. This configuration can work in two different modes namely, interconnected mode and islanded mode. UPQC - DG Separated configuration is shown in Fig.1 (b). A typical application of a UPQC might be to overcome the grid integration problems of the $\mathrm{DG}$, such as the fixed speed induction generator (FSIG). In case of line fault due to excessive reactive power requirement or grid voltage dip, the FSIG fails to remain connected to the grid. The drop in voltage creates over speeding of the turbine, which causes a protection trip. Fault-ride-through capability is achieved with the aid of the UPQC, which greatly enhances system stability. Connecting through UPQC may be the best solution in integration of wind energy system to the grid. UPQC can also be placed at the PCC to overcome voltage regulation problems in the case of a wind farm connected to a weak grid. The main problems for the configurations are i) the control complexity for active power transfer, ii) inability to provide harmonic and reactive power compensation during the islanded mode and iii) difficulty in the capacity enhancement in multi-level or multi-module mode. [9] Investigates a configuration of UPQC that has a DG connected to the dc link through the rectifier. The UPQC can compensate the voltage interruption in the source, while the DG supplies power to the source and load or the load only. In the interconnected mode shown in Fig.2 (a), the DG provides power to the source and the load. Whereas in islanding mode as shown in Fig. 2(b), DG will supply power to the load only within its power rating [10-11]. This apart, UPQC can inject power using DG to sensitive loads during source voltage interruption. The advantage of this system is voltage interruption compensation and active power injection to the grid in addition to the other normal UPQC abilities. [12, 13] discuss about the research and development carried out on the application of UPQC to grid-connected PV and wind energy systems. The reactive and harmonic currents drawn from nonlinear loads cannot be controlled by grid-connected PV inverter. As the UPQC is capable to compensate this problem, $\mathrm{PV}$ is connected to the DC link in the UPQC as an energy source. It can work both in interconnected and islanded mode. UPQC has the ability to inject power using PV to sensitive loads during source voltage interruption. The advantage of this system is voltage interruption compensation and active power injection to the grid in addition to the other normal UPQC abilities. But the system's functionality may be compromised if the solar resource is not sufficient during the voltage interruption condition. 


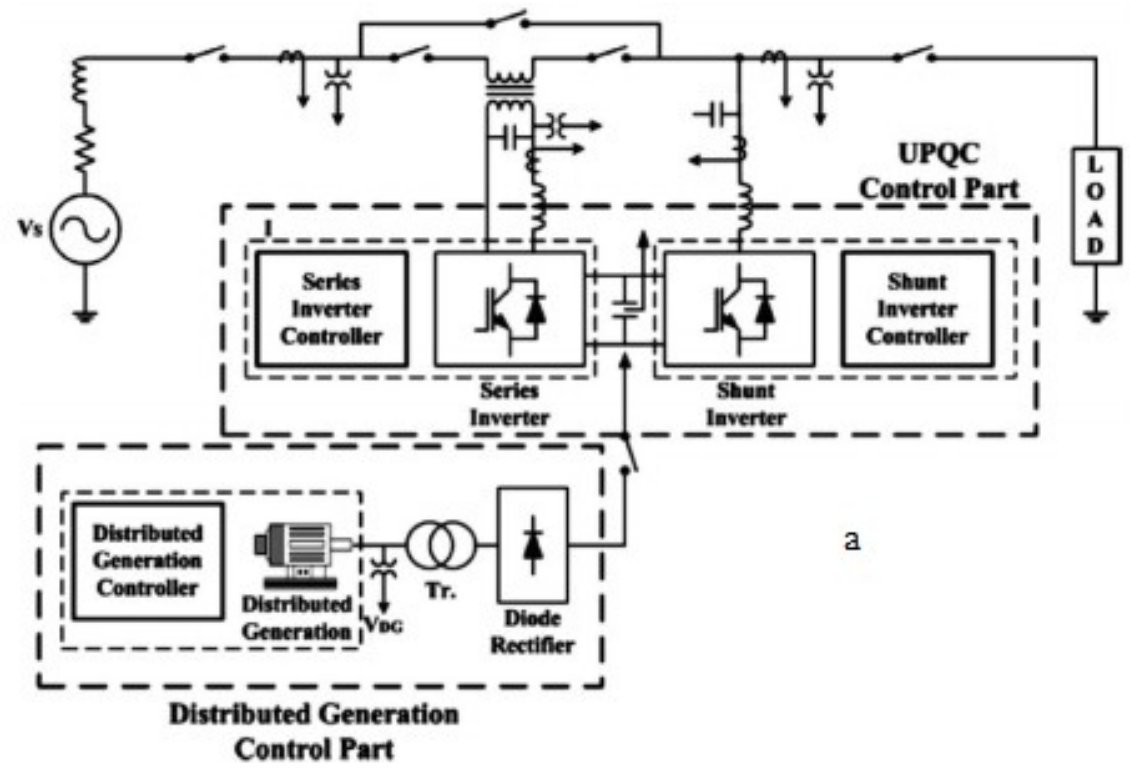

(a)

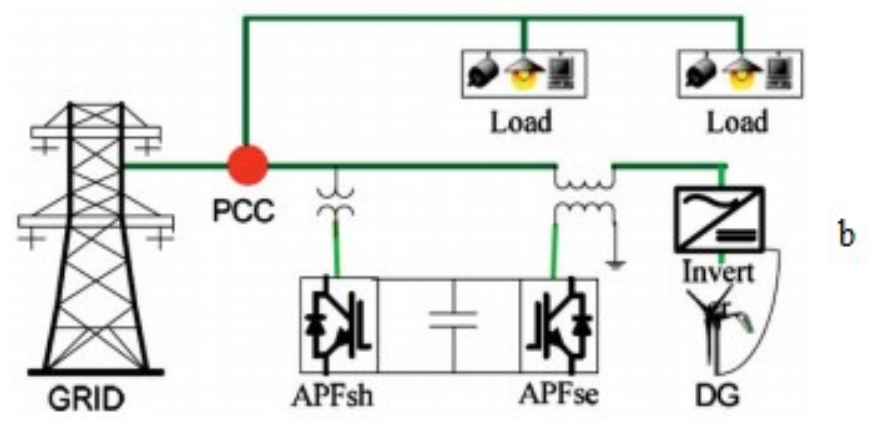

Fig 1. (a) UPQC -DG with DC link; (b) UPQC - DG separate
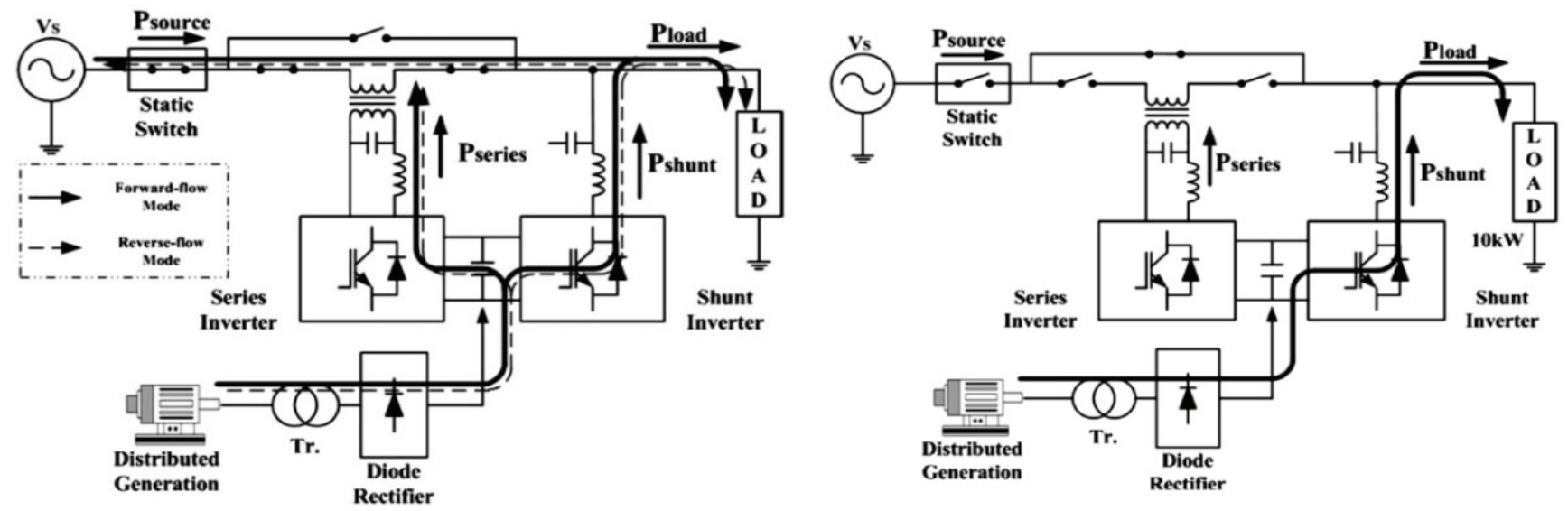

Fig. 2. (a) UPQC-DG in Grid interconnected mode (b) UPQC-DG in Islanding mode 

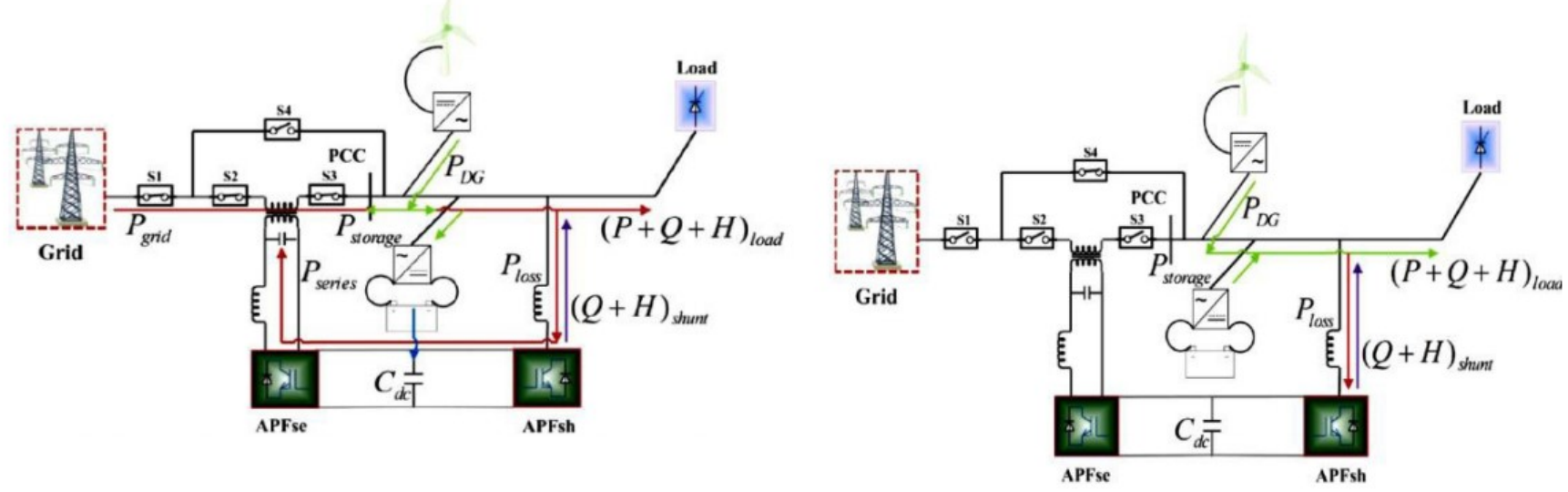

Fig. 3. (a) $\mathrm{UPQC}_{\mu \mathrm{G}}$ Inter Connected mode (b) $\mathrm{UPQC}_{\mu \mathrm{G}}$ Islanded mode

To extend the operational flexibility and to improve the power quality in grid connected $\mu \mathrm{G}$ systems, integration technique of UPQC has been proposed $[14,15]$. The $\mu \mathrm{G}$ system (with storage), the load and shunt part of the UPQC (APFsh) will be placed at or after the PCC. The series part of the UPQC (APFse) will be placed before the $\mathrm{PCC}$ and in series with the grid. DC link can be connected to the storage system also. Hence, it is termed UPQC $\mu \mathrm{G}$. The integration technique of the proposed $\mathrm{UPQC} \mu \mathrm{G}$ to a grid connected and DG integrated $\mu \mathrm{G}$ system and working principle during the interconnected and islanded mode for these configurations are shown in Fig. 3 (a) and Fig. 3(b). In Interconnected mode, DG source will deliver only the fundamental active power to the grid, storage and load. The APFsh will compensate the reactive and harmonic $(\mathrm{QH})$ power of the non-linear load to keep the THD at the PCC within the standard limit. Voltage sag/swell/ interruption can be compensated by the active power from the grid/storage through the APFse. DG converter will not sense any kind of voltage disturbance at the PCC and hence will remain connected in any condition. If the voltage interruption/black out occurs then UPQC will send a signal to the DG converter to be islanded. Whereas in Islanded mode, the APFse will be disconnected during the grid failure and DG converter will remain connected and maintain the required voltage at PCC. The APFsh will still compensate the non-active power of the non-linear load to provide or maintain undistorted current at PCC for other linear loads (if any). Therefore, DG converter (with storage) will deliver only the active power and hence does not need to be disconnected from the system. The APFse will be reconnected once the grid power is available [16].

\section{CONCLUSION}

It has been observed from the study that need for distributed generation is going to increase at a very fast rate in upcoming future. At the same time, fast rate advancement in $\mathrm{PE}$ technology has made it possible to integrate it with grid. The UPQC -DG has experimentally proved its capability to tackle all Power Quality issues very efficiently. So many more topological combinations of UPQC for different needs are yet to be explored.

\section{REFERENCES}

1. G. Pepermans, J. Driesen, D. Haeseldonckx, R. Belmans, W. D'haeseleer,Distributed generation: definition, benefits and issues, Energy Policy, vol. 33, p. 787-798, 2005.

2. F. V. Edwards, G. J. W. Dudgeon, J. R. McDonald and W. E. Leithead, Dynamics of distribution network with Distributed Generation, IEEE/ PES summer meeting 2000, Vol. 2.

3. M. I. Marei, E. F. El-Saadany and M. M. A.Salama ,Flexible Distributed Generation: (FDG) , IEEE International conference, Oct 2002.

4. Stefano Barsali, Massimo Ceraolo, Paolo Pelacchi, DavidePoli, Control techniques of Dispersed Generators to improve the continuity of electricity supply, International conference, 2002.

5. El-Samahy, El-Saadany, The Effect of DG on Power Quality in a Deregulated Environment, IEEE Power Engineering Society General Meeting 2005, p.2969-2976.

6. Ghosh and G. Ledwich, Power quality enhancement using custom power devices, Kluwer Academic, 2002 
7. S.K.Khadem, M.Basu and M.F.Conlon,Power Quality in Grid connected Renewable Energy Systems : Role of Custom Power Devices, International Conference and Power Quality (ICREPQ' 10), March 2010

8. S. K. Khadem, M. Basu and M. F. Conlon, Integration of UPQC for Power Quality Improvement in Distributed Generation Network - A Review

9. Y. Chen, X. Zha, and J. Wang, Unified power quality conditioner (UPQC): The theory, modeling and application, Proc. Power System Technology Power Con Int. Conf., vol. 3, 2000, p. 1329-1333.

10. M. I. Marei, E. F. El-Saadany, and M. M. A. Salama, Flexible distributed generation: (FDG), Proc. IEEE Power Engineering Soc. Summer Meeting, vol. 1, 2002, p. 49-53.

11. S. Barsali, M. Ceraolo, P. Pelacchi, and D. Poli, Control techniques of dispersed generators to improve the continuity of electricity supply, Proc.
IEEE Power Eng. Soc. Winter Meeting, vol. 2, 2002, p. 789-794.

12. M Hosseinpour, Y Mohamadrezapour, S Torabzade, Combined operation of Unifier Power quality conditioner and Photovoltaic Array, J of Applied Sciences, 2009, p. 680-688

13. Jayanti, N. G., M. Basu, Rating requirements of the unified power quality conditioner to integrate the fixed speed induction generator-type wind generation to the grid, IEEE 1547, IEEE Standard for Interconnecting Distributed Generation with Electric Power Systems, 2003.

14. A Kahrobaeian, Y Mohamed, Interactive distributed generation interface for flexible micro grid operation in smart distribution systems, IEEE Trans SE, vol.3, p. 295-305, 2012.

15. B. Han, B. Bae, H. Kim and S.Baek, Combined operation of Unified Power Quality Conditioner with Distributed Generation, IEEE Transaction on Power Delivery, Vol. 21, No. 1, 2006 